\title{
Narratives of Persistence: Indigenous Negotiations of Colonialism in Alta and Baja California
}

\author{
Lee M. Panich, University of Arizona Press, Tucson, 2020. 240 pp., 20 figs., 4 tables, \\ index. $\$ 55.55$ cloth
}

\author{
Marianne Sallum (iD) Francisco Silva Noelli
}

Accepted: 2 July 2021

(C) Society for Historical Archaeology 2021

In the last decade, the archaeology of persistence has been developed to comprehend how indigenous groups made "pragmatic choices to resist, accommodate or avoid various colonial impositions" and other social interactions. From this perspective, Lee M. Panich offers a brilliant example of the state of the art of how we perceive ways of persisting and how memories of the past echo like solid references for actions in the present.

The archaeology of persistence started with studies about colonialism and indigenous communities in the United States, principally with the works of Steve Silliman and Panich himself. It offers a new approach to contexts marked by long historical trajectories, for example indigenous collectives, maroons, and the socalled "traditional communities" in the Americas.

Apart from persistence, it also problematizes the construction of narratives centered upon ethnocentric notions of history and models of demographic and cultural collapse, and how these contributed to erase indigenous histories. This is highlighted by the author, by means of examples of methodological countermeasures that show the reader the presence of these indigenous collectives in the long term, and portray their continuous

M. Sallum $(\bowtie)$

Museum of Archeology and Ethnology, University of São Paulo, São Paulo, SP 05508-070, Brazil

e-mail: marisallum@usp.br

F. S. Noelli

Centre of Archaeology, University of Lisbon, 1600-214 Lisbon, Portugal struggle against "ingrained cultural stereotypes and narratives of indigenous extinction."

The book is dedicated to the case study of two communities with different trajectories: the Paipai in the Mexican state of Baja California, and the Ohlone of the San Francisco Bay area, in northern California. The Paipai succeeded at remaining relatively isolated during the colonial period, sharing similar traditions with their neighbors but speaking different languages, in a context where "linguistic diversity was probably the norm."

In some situations, fearing violence against their families, the Paipai mixed with the regional Mexican population, actioning the Spanish language and playing with identities as it suited them and, when convenient, reserving the Catarineño ethnonym to deal with outsiders. Throughout the colonial period and the 20th century, they assumed the denomination of Paipai in relation to their neighbors, and their continued isolation contributed to maintain their language. The Ohlone experienced a trajectory with diverse setbacks imposed by colonialism, including deterritorialization. As Panich writes: "as a question of clarity, I reserve the term Ohlone" to describe groups whose ancestors spoke Costanoan languages, in the area located between the south of the San Francisco peninsula, the Santa Clara valley, and the East Bay. In the colonial period, these communities were strictly associated with the missions of San Francisco, Santa Clara, and San José, where they were artificially grouped by Spanish colonizers and, afterwards, by anthropologists. The Ohlone live in cities and have recently worked to revitalize their languages 
and traditional practices, forming the vanguard of public movements to protect their ancestral places from development, and participating in the interpretation of the colonial history of their region.

Panich highlights the necessity of the perception of the individual in each local history, and shows how they persisted as social groups since their first interactions with the religious missions, despite facing numerous forms of colonialism and other attempts at domination. Upon comparing the history of the two communities, the the author's focus is on their different forms of negotiation and accommodation, as two different strategies to remain Paipai and Ohlone, through continuity that "does not require stasis." A comparative approach of these two cases is present throughout the book, with an emphasis on the relationships between personal and community histories (at a micro scale) and the indigenous history of California itself (at a macro scale). On the one hand, the Paipai maintained social isolation, persisting with practices that could be easily identified by the outsider. On the other hand, the Ohlone lost their ancestral lands and their connections with practices of the past, making these harder to recognize by the external observer. In several moments, Panich transcribes comments from members of the communities that destabilize constructions of traditional narratives about their demise: "we are still here" (Paipai) and "the missions were not successful" (Salinan/Rumsien Ohlone). The book's arguments are also reinforced with those of indigenous scholars, such as Sonya Atalay: "[ $t$ ]he link between the indigenous past and the presence of contemporary natives demands both recognizing the persistence of indigenous communities, and honestly reckoning with the dark realities of colonialism"; and nonindigenous scholars, such as Juliana Barr: "[t]ime was not interrupted with the arrival of the Europeans, nor did it stop (and restart afterwards). Rather, the Europeans arrived and became involved in a tide of native events and processes, the currents of native history."

Panich explains in detail how the construction and reproduction of the idea of extinction was strengthened over time: (1) in the interpretation of culture from the Spanish missions in California, "relegating indigenous people to a romanticized past"; (2) in primary school curricula, which teach that the foundation of the missions marked the end of indigenous communities; (3) in the belief held by past anthropologists and governments that California's indigenous populations became so mixed and degraded that their descendants cannot be recognized as "Native Americans"; (4) in the politics of erasure centered on terminal narratives supported by a colonial epistemology that assumes the elimination of indigenous peoples either through violence, removal, or popular mythology.

The book is divided into six chapters designed with an interdisciplinary approach combining archaeology, material culture studies, oral narratives, and the reexamination of documental sources, structured in five different themes: (1) political and social organization, (2) subsistence economy, (3) technology and material culture, (4) ceremonial life, and (5) conflict. Another fundamental point of the book is the proposal to analyze cultural practices and the evidence for "continuous changes," rather than consider continuity and change as separate phenomena.

In the introduction, the author presents the key concepts that support the central debates in the construction of histories of persistence. The aim is to emphasize the connection between the "colonial period to the precontact past and also to our contemporary world," centered on recent critiques and the proliferation of studies that have stopped advocating for a separation between "prehistory" and "history." The chapters follow a chronological order that considers: (1) the precolonial ancestors of the Ohlone and Paipai, based on regional archaeological, ethnographic, and ethnohistorical evidence, to showcase that the Europeans encountered a dynamic indigenous context in the 16th century; (2) the initial period of interaction between indigenous groups and the outsiders who established a colonial presence, primarily Franciscan missionaries and Spanish soldiers; (3) the choices made in the initial missionary period and the maintenance of indigenous practices; (4) native persistence and the collapse of the missions; (5) the decades following the end of the missions and the violence and loss of territory suffered by the Ohlone, with emphasis on the ways they were able to maintain their communities; and (6) the difference between Paipai and Ohlone strategies at the beginning of the 20th century, in the face of socioeconomic conditions that resemble those that are still in place to this day.

The conclusion advocates for the revision of terminal narratives that perpetuate the erasure of indigenous history, highlighting examples from various parts of the world where indigenous peoples are questioning colonialist viewpoints and acting to maintain their communities. Much like the examples of the Paipai and Ohlone demonstrate, change and persistence are part of the same 
process, and no two groups followed the same path until the present.

The book is successful at explaining complex themes with a didactic verve that is accessible to a wide readership. By focusing on persistence and the importance of contemporary Paipai and Ohlone memories, Panich shows how erasure is a conversation about the epistemic violence by colonizers and academia, and that it has no base for the communities that have survived throughout the course of their histories.

Publisher's Note Springer Nature remains neutral with regard to jurisdictional claims in published maps and institutional affiliations. 